УдК $616.381-007.43-089: 616.381-072.1$

DOI 10.11603/2414-4533.2018.2.9184

ОВ. В. ГРУБНИК, З. Д. БУГРИДЗЕ, К. О. ВОРОТЫНЦЕВА

Одесский национальный медицинский университет

\title{
Выбор метода лечения рецидивных паховых грыж
}

\begin{abstract}
Цель работы: определить оптимальный метод оперативного вмешательства при рецидивных паховых грыжах.
Материалы и методы. В период с сентября 2007 года по май 2011 года на базе Одесской областной клинической больницы было проведено сравнительное рандомизированное исследование, которое включило 82 пациента с рецидивными паховыми грыжами. Причинами рецидивов после первой операции у 14 пациентов стало заживление послеоперационной раны, у 30 пациентов - использование сеток недостаточно больших размеров и в других 38 пациентов - рецидив наступил в связи с нарушением выполнения техники операции Лихтенштейна. Все 82 пациента были разделены на две группы, первая группа пациентов была прооперирована с помощью лапароскопических методов, вторая группа - с помощью операции методом Лихтенштейна.

Результаты исследований и их обсуждение. Трансабдоминальная преперитонеальная лапароскопическая пластика ТАРР была выполнена 40 пациентам, при этом ни в одном случае не было конверсии. В группе I продолжительность операции была (87 \pm 12$)$ минут. В группе II 42 пациентам была выполнена открытая герниопластика, продолжительность этой операции была немного больше, чем лапароскопическая, что объясняется техническими сложностями выделения из рубцов рецидивной грыжи, краев апоневроза, сетчатого трансплантата и паховой связки. Средняя продолжительность операции в группе ІІ была (112 \pm 15$)$ минут. При наблюдении за пациентами группы II в срок от 12 до 24 месяцев у 4 пациентов (9,5 \%) был выявлен рецидив грыжи.
\end{abstract}

Ключевые слова: лечение; рецидивная паховая грыжа; лапароскопические методы; метод Лихтенштейна.

Постановка проблемы и анализ последних исследований и публикаций. Лечение паховых грыж является актуальным вопросом на протяжении последних 150 лет. Пластика паховых грыж наиболее популярная операция, выполняемая общими хирургами всего мира. Частота рецидивов паховых грыж при использовании операции Лихтенштейна с использованием различных сетчатых трансплантатов составляет от 5 - 9 \% [2, 3]. Операции по поводу рецидивных паховых грыж являются достаточно сложными и требуют наличие выдающихся навыков оперирующего хирурга и знаний нормальной анатомии. Количество рецидивов после операций по поводу рецидивных паховых грыж составляет от 8 до 34 \% [5]. Некоторые авторы предлагают использовать преперитонеальную технику по методу Стоппа [1, $2,4]$. Но недостаток данного метода заключается в том, что он достаточно травматический при выполнении, а также сопровождается большим количеством таких серьезных послеоперационных осложнений, как серомы, гематомы и нагноение ран. Лапароскопическая герниопластика рецидивных паховых грыж ассоциируется с хорошей эффективностью несмотря на серьезные технические трудности во время операции [5]. Для определения какой метод лапароскопической операции является более эффективным, в нашей клинике было проведено сравнительное рандомизированное исследование.
Цель работы: определить оптимальный метод оперативного вмешательства при рецидивных паховых грыжах.

Материалы и методы. В период с сентября 2007 г. по май 2011 г. на базе Одесской областной клинической больницы было проведено сравнительное рандомизированное исследование, которое включило 82 пациента с рецидивными паховыми грыжами. Все 82 пациента статистически существенно не отличались друг от друга. Первоначально все пациенты были прооперированы по методу Лихтенштейна с использованием полипропиленовой сетки. Необходимо отметить тот факт, что только 8 больных (9,75 \%) ранее были прооперированы в нашей клинике, остальные 24 пациента (29,2 \%) были прооперированы в городских больницах и 50 пациентов (60,9%) в центральных районных больницах. Причинами рецидивов после первой операции у 14 пациентов стало заживления послеоперационной раны, у 30 пациентов - использование сеток недостаточно больших размеров и в других 38 пациентов - рецидив наступил в связи с нарушением выполнения техники операции Лихтенштейна.

Всем пациентам было проведено тщательное клиническое и лабораторное обследование. В обязательном порядке всем пациентам проводили ультразвуковую диагностику, зоны пахового канала, которая позволяла достоверно подтвердить 
наличие рецидива паховой грыжи. Одиннадцати пациентам потребовалось проведение компьютерной томографии малого таза и двум пациентам была выполнена магнитно-резонансная томография органов малого таза. Данные этих исследований также подтвердили наличие рецидива паховых грыж. При физической нагрузке 42 пациента жаловались на выраженный болевой синдром и наличие грыжевого выпячивания. У восьми пациентов (9,75 \%) боль отдавала в мошонку и в яичко со стороны рецидивной грыжи. Таким образом, для исключения серьезной сопутствующей урологической патологии этим пациентам было дополнительно назначено обследование уролога. Это выявило аденому предстательной железы без тяжелых нарушений диуреза у 9 пациентов (10,9 \%) и хронический простатит у 25 пациентов (30,48 \%). Перед выполнением операции по поводу рецидивных паховых грыж всех пациентов ознакомливали с различными методиками, с помощью которых можно вылечить грыжи, после чего пациенты добровольно подписывали согласования для участия в рандомизированном исследовании.

Рандомизацию выполняли слепым методом: ни хирург, ни пациент не знали до операции, каким образом будет выполнена пластика пахового канала. В день операции сообщалось, какой метод будет применен, и операцию проводили опытные хирурги, которые владели как методикой открытой пластики паховых грыж, так и методикой лапароскопической пластики грыж.

Все 82 пациента были разделены на две группы, пациентов первой группы прооперировали с помощью лапароскопических методов, второй группы - с помощью операции методом Лихтенштейна.

В первой группе 40 больным выполнена лапароскопическая трансабдоминальная преперитонеальная пластика ТАРР. Лапароскопическую пластику грыж выполняли после наложения пневмоперитонеума до 12 мм рт. ст., с использованием трех троакаров. Первый 10 мм троакар вводили в область пупка, два 5 мм троакара в правую и левую подвздошные области. Брюшина над грыжевым дефектом отсепаровывалась. Отделяли грыжевой мешок, который отделяли от элементов семенного канатика. В обязательном порядке с грыжевого канала выделялась липома, которая сопровождала грыжевой мешок, пластика внутреннего кольца грыжевого дефекта выполнялась с помощью сетчатых трансплантатов. В данной группе больных использовали два типа сеток, у 28 пациентов использовали полипропиленовые сетки раз- мером 10 х 12 см, эти сетки фиксировались с помощью 3-5 такеров. У 12 пациентов использовали полипропиленовые сетки с нитиноловым каркасом, которые благодаря своей форме плотно прилегали к тканям пахового канала и не требовали дополнительной фиксации такерами. После установки сеток в данной группе больных восстанавливалась целостность перитонеальной брюшины. Для этого выполняли сшивания листков брюшины с помощью непрерывной нитки Викрила 3,0 с интракорпоральным завязыванием узлов.

В группе II, 42 пациентам выполняли повторную герниопластику по модифицированной методике Лихтенштейна, при этом сетчатый трансплантат установлен при первой операции в некоторых случаях иссекался, а в тех случаях, когда выделение трансплантата было технически сложным или невозможным, устанавливали новый сетчатый трансплантат, поверх первого. При выполнении открытого метода операции вырезали старый послеоперационный рубец, рассекали апоневроз и выделяли элементы семенного канатика, после чего выявляли грыжевой дефект. Для закрытия грыжевого дефекта использовали достаточно большие сетки размером 10×15 см, сетку подшивали к пупартовой связке и к апоневрозу нерассасывающимися швами. Дренирование раны не выполняли.

В раннем послеоперационном периоде учитывали и фиксировали все осложнения, особенно выраженность болевого синдрома, наличие воспалительной реакции тканей и нарушение диуреза. Период наблюдения за пациентами составил от 12 до 24 месяцев. В отдаленные сроки пациентам выполняли тщательное клиническое и инструментальное обследование для диагностики возможного рецидива грыжи. Для обработки полученных данных использовали методы непараметрической медицинской статистики [6, 8].

Результаты исследований и их обсуждение. Трансабдоминальная преперитонеальная лапароскопическая пластика ТАРР была выполнена 40 пациентам, при этом ни в одном случае не было конверсии. В группе I продолжительность опера-

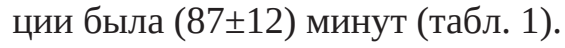

Серьезных интраоперационных осложнений при выполнении лапароскопических операций не замечено, однако технические трудности были у 18 пациентов при выделении грыжевого мешка и отделении его от элементов семенного канатика, что было обусловлено сращиванием грыжевого мешка с сетчатым трансплантатом. Таким образом, не всегда удавалось полностью выделить грыжевой 
Таблица 1. Характеристика операций

\begin{tabular}{|l|c|c|c||}
\hline \hline & Група I (n=40) & Група II (n=42) & P value \\
\hline Средняя длительность операции (мин.) & $38 \pm 7$ & $56 \pm 18$ & $<0.05$ \\
\hline Время, через которое пациенты начинали ходить (часы) & 12 & 24 & $<0.05$ \\
\hline Средняя длительность нахождения пациентов в стационаре (часы) & $12-18$ & $24-48$ & $<0.05$ \\
\hline $\begin{array}{l}\text { Время, через которое пациенты смогли вернуться к физическим } \\
\text { нагрузкам (дни) }\end{array}$ & $4-6$ & $7-10$ & $<0.05$ \\
\hline \hline
\end{tabular}

мешок, и его часть иссекалась и оставалась in situ. Сетчатый трансплантат устанавливался и фиксировался поверх семенного канатика у 21 пациентов. Для предотвращения возможного рецидива у 19 пациентов обычный полипропиленовый трансплантат рассекался до половины и одно крыло сетки заводилось под грыжевой мешок, после чего оба крыла сетки фиксировались такерами к передней брюшной стенки. В случаях, когда использовали сетки с нитиноловим каркасом, фиксацию не выполняли благодаря тому, что края нитиноловой рамки плотно упирались в ткани пахового канала. Небольшой отек мошонки наблюдался лишь у 8 больных (20 \%) данной лапароскопической группы (табл. 2).

Выраженный болевой синдром наблюдался только у одного пациента, которому была установлена сетка с нитиноловим каркасом большого размера, но после назначения ненаркотических анальгетиков боль прекратилась. Через 7-10 дней после операции трое больных обратились в больницу с жалобами на умеренную боль в области пахового канала, при выполнении ультразвуковой диагностики была обнаружена небольшая гематома между сеткой и париетальной брюшиной. Этим больным была назначена противовоспалительная терапия, после чего гематома рассасывалась в сроки от 3 до 5 недель. Уже на следующее утро пациенты после лапарсокпической операции смогли подниматься с постели и ходить, а на вторые сутки после операции были выписаны из стационара. Таким образом в среднем количество дней нахождения пациентов в стационаре составила $(3,5 \pm 1,4)$ дня. Все пациенты этой группы были удовлетворены ранними послеоперационными результатами. При наблюдении за пациентами в отдаленные сроки ни в одном случае не было выявлено рецидива грыжи. Лишь четыре пациента имели жалобы на наличие грыжеподобного выпячивания при кашле, но при выполнении ультразвуковой диагностики у этих пациентов четко прослеживался сетчатый трансплантат и не было обнаружено грыжевого дефекта пахового канала. Однако поскольку пациенты имели жалобы на наличие рецидива, им была выполнена компьютерная томография малого таза, которая также не подтвердила наличия рецидива грыжи. В отдаленные сроки после операции 9 пациентов (22,5 \%) имели жалобы на умеренные болевые ощущения в паховой области.

В группе II 42 пациентам была выполнена открытая герниопластика, продолжительность этой операции была немного больше, чем лапароскопическая, что объясняется техническими сложностями выделения из рубцов рецидивной грыжи, краев апоневроза, сетчатого трансплантата и паховой связки. Средняя продолжительность операции в данной группе пациентов была (112 \pm 15$)$ минут. Серьезных интраоперационных осложнений в данной группе больных не было. Выраженный болевой синдром наблюдался у 29 пациентов (69 \%) этой группы. Этим пациентам было необходимо назначение наркотических анальгетиков в первые дни после операции. Только 9 пациентов (21,4 \%) этой группы смогли подниматься и ходить через сутки после операции, другие пациенты начали ходить только через трое или четверо суток. Гематомы в области послеоперационной раны

Таблица 2. Послеоперационные осложнения

\begin{tabular}{||l|c|c|c||}
\hline & Група I (n=40) & Група II (n=42) & P value \\
\hline Отек мошонки & $8(20 \%)$ & $9(21,4 \%)$ & $>0,05$ \\
\hline Гематома & $3(7,5 \%)$ & $8(19,4 \%)$ & $<0,05$ \\
\hline Серома & $3(7,5 \%)$ & $15(35,7 \%)$ & $>0,01$ \\
\hline Грыжеподобное выпячивание & $4(10 \%)$ & $6(14,3 \%)$ & $>0,05$ \\
\hline Умеренный болевой синдром & $9(22,5 \%)$ & $7(16,5 \%)$ & $<0,01$ \\
\hline Выраженный болевой синдром & $1(2,5 \%)$ & $29(69 \%)$ & $<0,01$ \\
\hline Рецидив & 0 & $4(9,5 \%)$ & \\
\hline
\end{tabular}


были у 8 пациентов (19\%), отек мошонки у 9 пациентов (21,4 \%). Осложненный диурез в первые дни после операции имели 6 пациентов (14,2 \%). Температурная реакция с повышением температуры тела до 38 градусов была отмечена у 9 пациентов $(21,4 \%)$ в первые дни после операции. Серомы в подкожной клетчатке были сформированы у 15 пациентов (35,7 \%), десяти больным была назначена пункция серомы и у семи пациентов они самостоятельно вскрылись через рану. При наблюдении за пациентами этой группы в срок от 12 до 24 месяцев, у 4 пациентов (9,5 \%) был выявлен рецидив грыжи, 7 пациентов (16,6 \%) жаловались на сильную боль в паховой области при напряжении. Необходимо отметить, что при субъективном оценивании вмешательства восемь пациентов этой группы не были удовлетворены результатом открытого оперативного вмешательства.

При сравнении двух рандомизированных групп пациентов, которым была выполнена лапароскопическая и открытая операции по поводу рецидивных паховых гриж, мы определили четкие преимущества лапароскопических операций. Отсутствие серьезного болевого синдрома у пациентов после лапароскопических методов пластик объясняется меньшей травматичностью вмешательств, а также при использовании сеток с нитиноловым каркасом отсутствием фиксации сеток $[3,8]$. Несмотря на то, что лапароскопическая герниопластика требует наличия определенных навыков выполнения, продолжительность лапароскопической операции была несколько короче - 88 минуты, чем открытая операция - 119 минут. Эта разница в продолжительности операции ста-

\section{СПИСОК ЛИТЕРАТУРЫ}

1. Современные методы лечения брюшных грыж / В. В. Грубник, А. А. Лосев, Н. Р. Баязитов, Р. С. Парфентьев. - К. : Здоров’я, 2001. - 280 с.

2. Amid P. K. The Lichtenstein repair in 2002: an overview of causes of recurrence after Lichtenstein tension-free hernioplasty / A. K. Amid // Hernia. - 2003. - Vol. 7. - P. 13-16.

3. Lightweight mesh and noninvasive fixation: an effective concept for prevention of chronic pain with laparoscopic repair (TAPP) / R. Bittner, E. Gmahle, B. Gmahle [et al.] // Surg. Endosc. - 2010. - Vol. 24. - P. 2958-2964.

4. Elsebae M. M. Tension-free repair versus Bassini technique for strangulated inguinal hernia: a controlled randomized study / M. M. Elsebae, M. Nasr, M. Said // Int. J. Surg. - 2008. - Vol. 6. тистически недостоверна, хотя снижение времени при лапароскопическом вмешательстве отчетливо проявилось. Необходимо отметить, что для успешного выполнения лапароскопической пластики рецидивных паховых грыж необходимо наличие опыта оперирующего хирурга [7]. При определении частоты ранних и поздних осложнений нами выявлено статистически вероятно $(p<0,01)$ меньшее количество осложнений после лапароскопической герниоплатики, чем после открытой. Но наиболее существенным по нашему мнению явился тот факт, что после лапароскопических вмешательств не было рецидивов грыж, в то время как после открытых операций частота рецидивов составила 9,5 \%.

Выводы. Пациенты, которые были прооперированы с использованием лапароскопических методов, имеют определенные преимущества в продолжительности выполнения операции, количества послеоперационных осложнений, наличия болевого синдрома и самое главное, что у данных пациентов отсутствует рецидив грыжи. В техническом плане лапароскопическая герниопластика менее сложная, чем открытая операция, открытые операции достаточно травматичные, потому что есть технические проблемы при выделении элементов семенного канатика с рубцовых тканей. Лапароскопические операции обеспечивают надежную пластику грыжевого дефекта. Однако необходимы дальнейшие исследования, которые покажут преимущества лапароскопической методики как при сравнении ранних, так и отдаленных результатов.

\section{REFERENCES}

1. Grubnik, V.V., Losev, A.A., Bayazitov, N.R., \& Parfentyev, R.S. (2001). Sevremennye metody lecheniya bryushnikh grizh [Modern methods of treatment of abdominal hernia]. Kyiv: Zdorovia [in Russian].

- P. 302-305.

5. Keidar A. Laparoscopic repair of recurrent inguinal hernia / A. Keidar, S. Kanitkar, A. Szold // Surg. Endosc. - 2002. Vol. 16. - P. 1708-1712.

6. Kurzer M. Prospective study of open preperitoneal mesh repair for recurrent inguinal hernia / M. Kurzer, P. A. Belsham, A. E. Kark // Br. J. Surg.. - 2002. - Vol. 89. - P. 90-93.

7. Laparoscopic transabdominal preperitoneal (TAPP) hernia repair: surgical phases and complications / F. Lovisseto, S. Zonta, E. Rota [et al.] // Surg. Endosc. - 2006. - Vol. 21. - P. 646-652. 8. Randomized clinical trial of Lichtenstein patch or Prolene Hernia System for inguinal hernia repair / J. Vironen, J. Nieminen, A. Eklund, P. Paavolainen // Br. J. Surg. - 2006. - Vol. 93. - P. 33-39.
2. Amid, P.K. (2003). The Lichtenstein repair in 2002: an overview of causes of recurrence after Lichtenstein tension-free hernioplasty. Hernia, (7), 13-16.

3. Bittner, R., Gmahle, E., Gmahle, B., Schwarz, J., \& Kehlet, H. 
(2010). Lightweight mesh and noninvasive fixation: an effective concept for prevention of chronic pain with laparoscopic repair (TAPP). Surgical Endoscopy, 24 (3), 2958-2964.

4. Elsebae, M.M., Nasr, M., \& Said, M. (2008). Tension-free repair versus Bassini technique for strangulated inguinal hernia: a controlled randomized study. Int. Journal Surgery, 6 (3), 302305.

5. Keidar, A., Kanitkar, S., \& Szold, A. (2002). Laparoscopic repair of recurrent inguinal hernia. Surgical Endoscopy, 16 (4), $1708-1712$.
6. Kurzer, M., Belsham, P.A., \& Kark, A.E. (2002) Prospective study of open preperitoneal mesh repair for recurrent inguinal hernia. British Journal Surgery, 89 (1), 90-103.

7. Lovisseto, F., Zonta, S., Rota, E., Bottero, L., Faillace, G., Turra, G., Fantini, A., \& Longoni, M. (2006). Laparoscopic transabdominal preperitoneal (TAPP) hernia repair: surgical phases and complications. Surgical Endoscopy, 21 (5), 646-652. 8. Vironen, J., Nieminen, J., \& Eklund, A. (2006) Randomized clinical trial of Lichtenstein patch or Prolene Hernia System for inguinal hernia repair. British Journal Surgery, 9 (3), 33-39.

Отримано 28.02.2018

V. V. GRUBNIK, Z. D. BUGRIDZE, K. O. VOROTYNTSEVA

Odesa National Medical University

\section{CHOICE OF TREATMENT METHOD OF RECURRENT INGUINAL HERNIA}

The aim of the work: to determine the optimal method of surgical operation for recurrent inguinal hernias.

Materials and Methods. In the period from September 2007 to May 2011, a comparative randomized study was conducted at the Odesa Regional Clinical Hospital, which included 82 patients with recurrent inguinal hernias. The cause of relapse after the first operation in 14 patients was the healing of the postoperative wound, in 30 patients - the use of meshes insufficiently large, and in the other 38 patients - the relapse occurred due to a violation of the technique of the operation of Lichtenstein. All 82 patients were divided into two groups. The first group of patients was operated with laparoscopic methods, the second group - with the help of the Lichtenstein method.

Results and Discussion. Transabdominal preperitoneal laparoscopic (TAPP) was performed in 40 patients, with no conversion in any case. In group I, the duration of the operation was (87 \pm 12$)$ minutes. In group II, 42 patients underwent open hernioplasty, the duration of this operation was slightly greater than the laparoscopic one, which is explained by the technical difficulties in the isolation of the scars of the recurrent hernia, the edges of the aponeurosis, the graft and the inguinal ligament. The average duration of surgery in group II was $(112 \pm 15)$ minutes. When patients of group II were monitored for 12 to 24 months, 4 patients (9.5 \%) had a recurrent hernia.

Key words: treatment; recurrent inguinal hernia; laparoscopic methods; Lichtenstein’s method.

\section{В. В. ГРУБНІК, З. Д. БУГРІДЗЕ, К. О. ВОРОТИНЦЕВА}

Одеський національний медичний університет

\section{ВИБІР МЕТОДУ ЛІКУВАННЯ РЕЦИДИВНИХ ПАХВИННИХ ГРИЖ}

Мета роботи: визначити оптимальний метод оперативного втручання при рецидивних пахвинних грижах.

Матеріали і методи. У період з вересня 2007 р. до травня 2011 р. на базі Одеської обласної клінічної лікарні проведено порівняльне рандомізоване дослідження, яке включило 82 пацієнта з рецидивними пахвинними грижами. Причинами рецидивів після першої операції у 14 пацієнтів стало загоєння післяопераційної рани, у 30 пацієнтів - використання сіток недостатньо великих розмірів і в інших 38 пацієнтів - рецидив виникав внаслідок порушення виконання техніки операції Ліхтенштейна. Всі 82 пацієнта розділені на дві групи, перша група пацієнтів була прооперована за допомогою лапароскопічних методів, друга група - за допомогою операції методом Ліхтенштейна.

Результати досліджень та їх обговорення. Трансабдомінальну преперитонеальну лапароскопічну пластику ТАРР виконано 40 пацієнтам, при цьому ні в одному випадку не було конверсії. У групі І тривалість операції була (87 \pm 12$)$ хвилин. У групі II 42 пацієнтам виконано відкриту герніопластику, тривалість цієї операції була трохи більше, ніж лапароскопічна, що пояснюється технічними складнощами виділення з рубців рецидивної грижі, країв апоневрозу, сітчастого трансплантата і пахвинної зв'язки. Середня тривалість операції в групі II була (112 \pm 15$)$ хвилин. При спостереженні за пацієнтами групи II в термін від 12 до 24 місяців у 4 пацієнтів (9,5 \%) виявлено рецидив грижі.

Ключові слова: лікування; рецидивна пахвинна грижа; лапароскопічні методи; метод Ліхтенштейна. 